\title{
Pregnancy outcomes of dichorionic triamniotic triplet pregnancies after in vitro fertilization-embryo transfer: multifoetal pregnancy reduction versus expectant management
}

Pei Cai ${ }^{1}$, Yan Ouyang ${ }^{2}$, Fei Gong ${ }^{1,2}$ and Xihong $\mathrm{Li}^{2^{*}}$ (1)

\begin{abstract}
Background: Trichorionic triplet pregnancy reduction to twin pregnancy is associated with a lower risk of preterm delivery but not with a lower risk of miscarriage. However, data on dichorionic triamniotic (DCTA) triplet pregnancy outcomes are lacking. This study aimed to compare the pregnancy outcomes of DCTA triplets conceived via in vitro fertilization-embryo transfer (IVF-ET) managed expectantly or reduced to a monochorionic (MC) singleton or monochorionic diamniotic (MCDA) twins at $11-13^{+6}$ gestational weeks.

Methods: Two hundred ninety-eight patients with DCTA triplets conceived via IVF-ET between 2012 and 2016 were retrospectively analysed. DCTA triplets with three live foetuses were reduced to a MC singleton (group A) or MCDA twins (group B) or underwent expectant management (group C). Each multifoetal pregnancy reduction (MFPR) was performed at $11-13^{+6}$ gestational weeks. Pregnancy outcomes in the 3 groups were compared.

Results: Eighty-four DCTA pregnancies were reduced to MC singleton pregnancies, 149 were reduced to MCDA pregnancies, and 65 were managed expectantly.

There were no significant differences among groups $A, B$, and $C$ in miscarriage rate ( 8.3 vs. 7.4 vs. $10.8 \%$, respectively) and live birth rate ( 90.5 vs. 85.2 vs. $83.1 \%$, respectively) $(P>0.05)$.

Group A had significantly lower rates of preterm birth (8.3 vs. 84.6\%; odds ratio (OR) $0.017,95 \%$ confidence interval (Cl) 0.006-0.046) and low birth weight (LBW; 9.2 vs. 93.2\%; OR 0.007, 95\% Cl 0.003-0.020) than group C $(P<0.001)$.

Group B had significantly lower preterm birth (47.0 vs. 84.6\%; OR 0.161, 95\% Cl 0.076-0.340) and LBW rates (58.7 vs. 93.2\%; OR 0.103, 95\% Cl 0.053-0.200) than group C $(P<0.001)$.

Group A had significantly lower preterm birth (8.3 vs. 47.0\%; OR 0.103, 95\% Cl 0.044-0.237; $P<0.001$ ), LBW (9.2 vs. 58.7\%; OR $0.071,95 \% \mathrm{Cl} 0.032-0.162 ; P<0.001)$ and perinatal death rates $(1.3$ vs. 9.1\%; OR $0.132,95 \% \mathrm{Cl} 0.018-0.991 ; P=0.021)$ than group B.

(Continued on next page)
\end{abstract}

\footnotetext{
* Correspondence: xihongliyxk@163.com

${ }^{2}$ Reproductive and Genetic Hospital of CITIC-Xiangya, Changsha City 410078, Hunan, China

Full list of author information is available at the end of the article
}

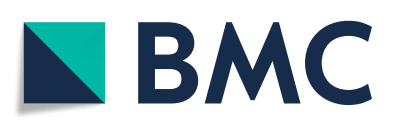

(c) The Author(s). 2020 Open Access This article is licensed under a Creative Commons Attribution 4.0 International License, which permits use, sharing, adaptation, distribution and reproduction in any medium or format, as long as you give appropriate credit to the original author(s) and the source, provide a link to the Creative Commons licence, and indicate if changes were made. The images or other third party material in this article are included in the article's Creative Commons licence, unless indicated otherwise in a credit line to the material. If material is not included in the article's Creative Commons licence and your intended use is not permitted by statutory regulation or exceeds the permitted use, you will need to obtain permission directly from the copyright holder. To view a copy of this licence, visit http://creativecommons.org/licenses/by/4.0/ The Creative Commons Public Domain Dedication waiver (http://creativecommons.org/publicdomain/zero/1.0/) applies to the data made available in this article, unless otherwise stated in a credit line to the data. 
(Continued from previous page)

Conclusion: The MFPR of DCTA triplets to singleton or MCDA pregnancies was associated with better pregnancy outcomes compared to expectant management. DCTA triplets reduced to singleton pregnancies had better perinatal outcomes than DCTA triplets reduced to MCDA pregnancies.

Keywords: Dichorionic triamniotic triplet pregnancies, Multifoetal pregnancy reduction, In vitro fertilization-embryo transfer, Pregnancy outcomes

\section{Background}

Over the past few decades, there has been a dramatic increase in the incidence of multifoetal pregnancies (MFPs) due to advancing maternal age, the widespread application of assisted reproductive technology (ART) and the use of ovulation induction drugs [1-3]. As a result of restrictions on the number of embryos transferred in women undergoing ART, a decline in MFPs has been observed in recent years $[4,5]$. However, the splitting of one embryo into two embryos may lead to higher-order multiple pregnancies (HOMPs), including triplet pregnancies containing monochorionic (MC) twins [5-8].

Compared with singleton and twin pregnancies, HOMPs are associated with a higher risk of maternal-perinatal and long-term complications [9-12] and increased hospital costs [13]. Compared with singleton and twin pregnancies, triplet pregnancies are at a higher risk of miscarriage and preterm birth [5, 14-17]. To reduce the risks associated with triplet pregnancies and HOMPs $[18,19]$, multifoetal pregnancy reduction (MFPR) has been performed in recent years, and several methods have been described [20,21]. There is ample evidence that reducing quadruplet-or-higher pregnancies to twins is associated with more favourable outcomes, including advanced gestational age (GA) at delivery [15, 16, 22]. A meta-analysis [23] showed that trichorionic triplet pregnancy reduction to a twin pregnancy is associated with a lower risk of preterm delivery with no significant increase in the miscarriage rate. However, data on the perinatal outcomes of women with dichorionic triamniotic (DCTA) triplet pregnancies who undergo MFPR are lacking, and two metaanalyses on this subject reported that the numbers are insufficient to recommend one technique over another or to draw clear conclusions on the perinatal outcomes of DCTA pregnancies [3, 23].

The aim of this study was to investigate the pregnancy and obstetric outcomes of women with DCTA pregnancies conceived by IVF-ET that were managed expectantly or were reduced to singleton pregnancies (foetus with a separate placenta) or monochorionic diamniotic (MCDA) twin pregnancies at $11-13^{+6}$ gestational weeks.

\section{Material and methods}

\section{Patients}

A retrospective analysis was conducted of infertile patients with DCTA pregnancies conceived via IVF-ET from January 2012 to December 2016 at the Reproductive and Genetic Hospital of CITIC-Xiangya (Changsha City, Hunan, China). This study was approved by the Ethics Committee of the Reproductive and Genetic Hospital of CITIC-Xiangya.

We identified 476 infertile patients who conceived DCTA triplets via IVF-ET. The IVF and ET procedures were carried out as previously described [24]. Chorionicity was determined during the first trimester by ultrasound based on the number of placental sites, the presence of the "lambda sign" or "T sign" in a single placenta, and an evaluation of interfoetal membranes by experienced radiologists [25]. Only those who underwent IVF-ET, ultrasound examinations and MFPR at our hospital were included in this study. Patients who experienced spontaneous reductions or pregnancy loss $(n=176)$ before $11-$ $13^{+6}$ gestational weeks, referred to other centers for intrafoetal laser ablation $(n=1)$ or were lost to follow-up ( $n=$ $1)$ were excluded from this analysis. Finally, 298 patients with DCTA pregnancies with three viable foetuses until $11-13^{+6}$ gestational weeks were included in the data analysis (Fig. 1). When a foetal heartbeat was detected by ultrasound, the pregnancy was considered viable. GA was based on the date of embryo transfer (ET) plus 17 or 19 days for day 3 embryo or blastocyst transfers, respectively.

\section{MFPR procedure}

All patients were counselled regarding the risks of a DCTA pregnancy and the different management options, including MFPR (including the injection and vascular-occlusive techniques, such as intrafoetal laser ablation) and expectant management. Patients were informed in detail about the risks and benefits of MFPR. Given the lack of clear evidence regarding the best method for MFPR and the psychological impact of reduction on patients, the final choice was based mostly on patient preference. Because intrafoetal laser ablation was not performed at our centre, patients considered this technique were referred to a second centre. Patients who decided to undergo foetal reduction at our centre followed our routine foetal reduction procedure. The reasons for MFPR were either structural abnormalities (such as abnormal foetal nuchal translucency (NT), severe foetal cardiac malformations and foetal limb defects) in one or two of the foetuses or patient preference. 


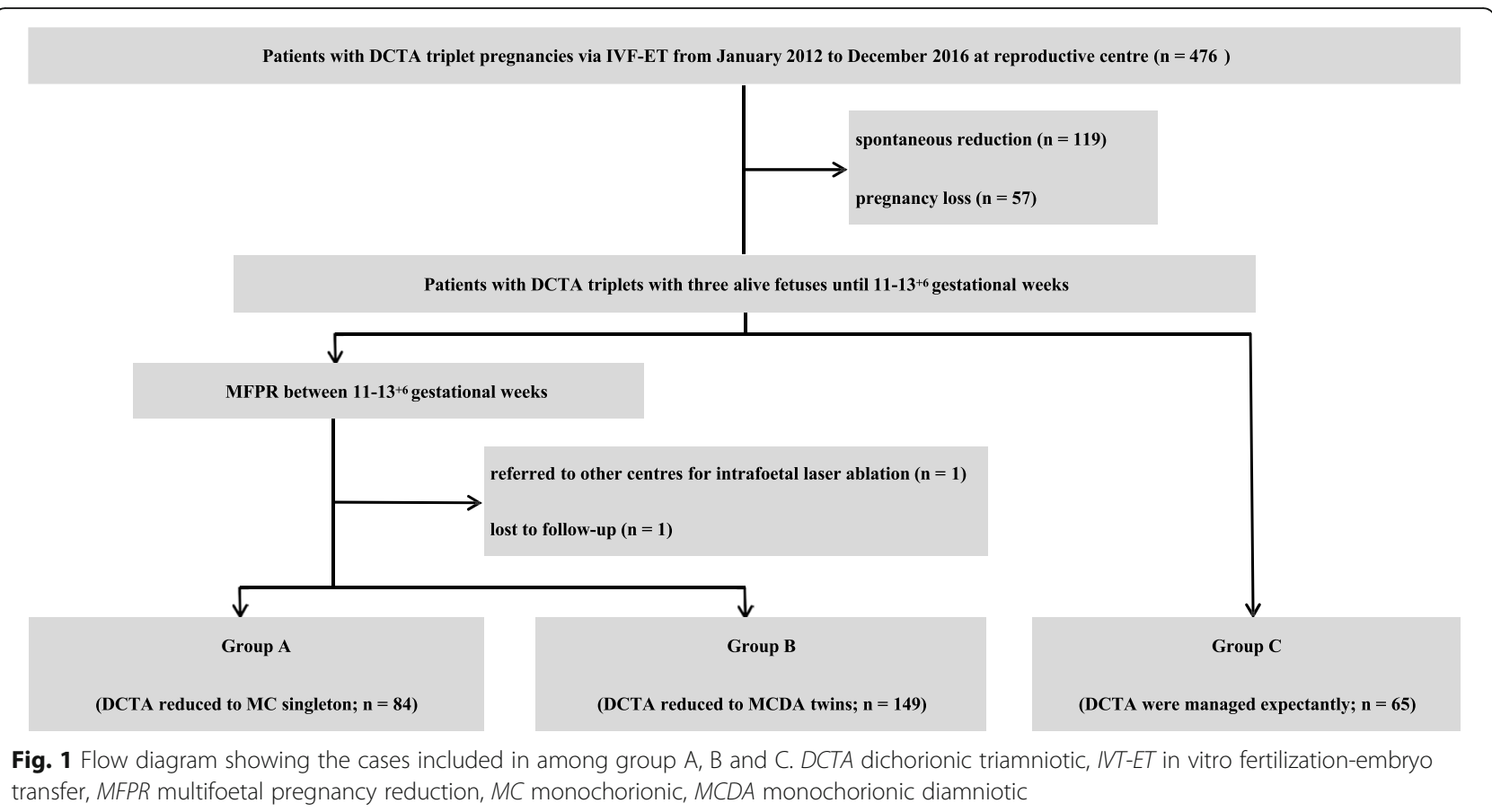

Written informed consent for foetal reduction was obtained from each participant. The procedure was performed transabdominally by the ultrasound-guided intrathoracic injection of potassium chloride $(10 \% \mathrm{KCl}$, $2 \mathrm{ml}$ ) using a $20 \mathrm{G}$ spinal needle $(15 \mathrm{~cm}$ in length). All reductions were performed by a highly skilled physician (Dr Yan Shen). MFPRs were performed at $11-13^{+6}$ gestational weeks (58-80 days after ET) after a NT scan. The selection of foetuses to be reduced was based on the NT scan and accessibility. If one or both of the MCDA twins in the DCTA pregnancy had an abnormal NT or (and) certain other structural abnormalities, both were reduced, and if the MC singleton of the DCTA pregnancy had an abnormal NT or (and) certain other structural abnormalities, this foetus was reduced. If the ultrasound scan showed no abnormality in any foetus, patient preference and foetal accessibility dictated the reduction of the MC singleton or MCDA twins. An abnormal (increased) NT was defined as a foetal NT of $3 \mathrm{~mm}$ or more detected by ultrasound examination in the first trimester [26].

\section{Outcome measures}

Maternal demographics, ultrasound findings and IVF-ET and MFPR procedure details were recorded in the medical records. The pregnancy and obstetric outcomes were followed up by telephone or fax. The pregnancy and perinatal outcomes were defined as follows: miscarriage: pregnancy loss before 24 gestational weeks; preterm birth: delivery at a minimum of 24 gestational weeks but before 37 gestational weeks; very preterm birth (VPB): delivery at or later than 24 gestational weeks but before 32 gestational weeks; and term birth: delivery at or later than 37 gestational weeks but before 42 gestational weeks [5]. Additionally, intrauterine death (IUD) was defined as foetal demise from 24 gestational weeks. Perinatal death included IUD and neonatal death (NND) of live-born infant during the first 28 days [27]. Low birth weight (LBW) was defined as a birth weight of less than $2500 \mathrm{~g}$, and very low birth weight (VLBW) was defined as a birth weight of less than $1500 \mathrm{~g}$ [28].

\section{Statistical analysis}

Statistical analyses were conducted using SPSS version 17.0 software (SPSS, Inc., Chicago, IL, USA). Descriptive statistics are presented as the means \pm standard deviations (SDs) and as percentages for enumerated data. Differences in the means between the two groups were analysed using Student's t-test. The chi-squared test or Fisher's exact test was used to determine the statistical significance of differences between percentages. Statistical significance was set at $P<0.05$.

\section{Results}

Eighty-four DCTA triplets were reduced to MC singleton pregnancies (group A), 149 DCTA triplet pregnancies were reduced to MCDA twin pregnancies (group B), and 65 DCTA pregnancies were managed expectantly (group C).

Groups A, B and C were statistically similar regarding maternal age ( $29.6 \pm 4.2$ vs. $29.4 \pm 3.9$ vs. $28.4 \pm 3.7$ years), body mass index ( $21.5 \pm 2.7$ vs. $21.7 \pm 3.0$ vs. $21.9 \pm 3.1 \mathrm{~kg} /$ 
$\left.\mathrm{m}^{2}\right)$, infertility duration $(4.4 \pm 3.5$ vs. $4.3 \pm 2.8$ vs. $4.1 \pm 3.2$ years), transfer cycles ( $1.2 \pm 0.5$ vs. $1.1 \pm 0.5$ vs. $1.1 \pm 0.5)$, infertility type, cause of infertility, and insemination methods $(P>0.05)$ (Table 1$)$.

Group A had significantly lower rates of preterm birth (8.3 vs. $84.6 \%$; odds ratio (OR) $0.017,95 \%$ confidence interval (CI) 0.006-0.046), VPB (2.6 vs. 22.4\%; OR 0.092, 95\% CI $0.020-0.428$ ), LBW (9.2 vs. 93.2\%; OR 0.007, 95\% CI $0.003-0.020)$ and perinatal death (1.3 vs. 9.8\%; OR 0.122 , 95\% CI $0.016-0.930)$ than group $C(P<0.05)$. GA at delivery ( $38.5 \pm 2.1$ vs. $33.4 \pm 3.0$ weeks $)$ and live birth weight ( $3168 \pm 557$ vs. $1827 \pm 441 \mathrm{~g})$ were significantly higher in group A than in group $C(P<0.001)$. There was no significant difference in the miscarriage rate $(8.3$ vs. $10.8 \%)$ and the live birth rate $(90.5$ vs. 83.1\%) between groups $\mathrm{A}$ and $\mathrm{C}(P>0.05)$ (Table 2).

Group B had significantly lower rates of preterm birth (47.0 vs. $84.6 \%$; OR $0.161,95 \%$ CI $0.076-0.340$ ), VPB (7.2 vs. 22.4\%; OR 0.270, 95\% CI $0.111-0.660$ ) and LBW (58.7 vs. 93.2\%; OR 0.103, 95\% CI 0.053-0.200) than group $\mathrm{C}(P<0.05)$. In addition, GA at delivery $(35.7 \pm 3.1$ vs. $33.4 \pm 3.0$ weeks) and live birth weight $(2348 \pm 488$ vs. $1827 \pm 441 \mathrm{~g})$ were significantly higher in group $\mathrm{B}$ than in group $\mathrm{C}(P<0.001)$. There was no significant difference in the miscarriage rate ( 7.4 vs. $10.8 \%$ ) and the live birth rate ( 85.2 vs. $83.1 \%)$ between groups B and $C(P>0.05)$ (Table 3$)$.

Group A had significantly lower rates of preterm birth (8.3 vs. $47.0 \%$; OR 0.103, 95\% CI 0.044-0.237), LBW (9.2 vs. 58.7\%; OR 0.071, 95\% CI 0.032-0.162) and perinatal death (1.3 vs. 9.1\%; OR 0.132, 95\% CI 0.018-0.991) than group B $(P<0.05)$. Additionally, GA at delivery $(38.5 \pm$ 2.1 vs. $35.7 \pm 3.1$ weeks) and live birth weight (3168 \pm 557 vs. $2348 \pm 488 \mathrm{~g}$ ) were significantly higher in group A than in group B $(P<0.001)$. However, there was no significant difference in the miscarriage rate (8.3 vs. $7.4 \%)$ and the live birth rate $(90.5$ vs. $85.2 \%)$ between groups A and B $(P>0.05)$ (Table 4$)$.

\section{Discussion}

In the present study, we analysed the pregnancy and obstetric outcomes of women with DCTA pregnancies conceived by IVF-ET who underwent MFPR at $11-13^{+6}$ gestational weeks or expectant management. We found that the MFPR of DCTA pregnancies to either MC singleton or MCDA twin pregnancies improved the pregnancy and obstetric outcomes by significantly decreasing the risks of preterm birth, VPB and LBW and significantly increasing the GA at delivery and live birth weight, with no significant reduction in the miscarriage risk. Specifically,

Table 1 Comparison of the maternal demographic characteristics among groups A, B and C

\begin{tabular}{|c|c|c|c|c|c|c|}
\hline characteristic & $\begin{array}{l}\text { Group A } \\
(n=84)\end{array}$ & $\begin{array}{l}\text { Group B } \\
(n=149)\end{array}$ & $\begin{array}{l}\text { Group C } \\
(n=65)\end{array}$ & $\begin{array}{l}\text { Group A vs. Group C } \\
P \text { - value }\end{array}$ & $\begin{array}{l}\text { Group B vs. Group C } \\
P \text { - value }\end{array}$ & $\begin{array}{l}\text { Group A vs. Group B } \\
P \text { - value }\end{array}$ \\
\hline Maternal age (years) & $29.6 \pm 4.2$ & $29.4 \pm 3.9$ & $28.4 \pm 3.7$ & NS & NS & NS \\
\hline $\mathrm{BMI}\left(\mathrm{kg} / \mathrm{m}^{2}\right)$ & $21.5 \pm 2.7$ & $21.7 \pm 3.0$ & $21.9 \pm 3.1$ & NS & NS & NS \\
\hline Infertility duration (years) & $4.4 \pm 3.5$ & $4.3 \pm 2.8$ & $4.1 \pm 3.2$ & NS & NS & NS \\
\hline Infertility type & & & & NS & NS & NS \\
\hline Primary, n (\%) & $39(46.4)$ & $62(41.6)$ & $36(55.4)$ & & & \\
\hline Secondary, n (\%) & $45(53.6)$ & $87(58.4)$ & $29(44.6)$ & & & \\
\hline Cause of infertility & & & & NS & NS & NS \\
\hline Male factor, n (\%) & $58(69.0)$ & $94(63.1)$ & $47(72.3)$ & & & \\
\hline Female factor, n (\%) & $3(3.6)$ & $3(2.0)$ & $1(1.5)$ & & & \\
\hline Female + male factors, n (\%) & $23(27.4)$ & $49(32.9)$ & $14(21.5)$ & & & \\
\hline Unexplained, n (\%) & $0(0)$ & $3(2.0)$ & $3(4.6)$ & & & \\
\hline Transfer cycle & $1.2 \pm 0.5$ & $1.1 \pm 0.5$ & $1.1 \pm 0.5$ & NS & NS & NS \\
\hline $1, \mathrm{n}(\%)$ & $72(85.7)$ & $135(90.6)$ & $58(89.2)$ & NS & NS & NS \\
\hline$\geq 2, n(\%)$ & $12(14.3)$ & $14(9.4)$ & $7(10.8)$ & & & \\
\hline Insemination methods & & & & NS & NS & NS \\
\hline IVF, n (\%) & $49(58.3)$ & $96(64.4)$ & $45(69.2)$ & & & \\
\hline ICSI, n (\%) & $9(10.7)$ & $20(13.4)$ & $9(13.8)$ & & & \\
\hline IVF/ICSI, n (\%) & $26(31.0)$ & $33(22.1)$ & $11(16.1)$ & & & \\
\hline
\end{tabular}

Group A = DCTA pregnancy reduced to MC singleton pregnancy; Group B = DCTA pregnancy reduced to MCDA twin pregnancy; Group C = DCTA pregnancy were managed expectantly

DCTA dichorionic triamniotic, MC monochorionic, MCDA monochorionic diamniotic, BMI body mass index, NS not significant, IVF in vitro fertilization, ICSI intracytoplasmic sperm injection 
Table 2 Pregnancy and obstetric outcomes in group A and group C

\begin{tabular}{|c|c|c|c|c|}
\hline Pregnancy outcomes & Group A & Group C & $P$-value & OR $(95 \% \mathrm{Cl})$ \\
\hline Pregnancy & 84 & 65 & & \\
\hline Miscarriage rate, $\%(n)$ & $8.3(7 / 84)$ & $10.8(7 / 65)$ & 0.613 & $0.753(0.250-2.267)$ \\
\hline Preterm birth rate, $\%$ (n) & $8.3(7 / 84)$ & $84.6(55 / 65)$ & $<0.001$ & $0.017(0.006-0.046)$ \\
\hline Term birth rate, \% (n) & $83.3(70 / 84)$ & $4.6(3 / 65)$ & $<0.001$ & $103.333(28.361-376.496)$ \\
\hline Caesarean section rate, \% (n) & $68.8(53 / 77)$ & $87.9(51 / 58)$ & 0.009 & $0.303(0.120-0.765)$ \\
\hline Babies born & 77 & 174 & & \\
\hline Live births & 76 & 162 & & \\
\hline Live birth rate, \% (n) & $90.5(76 / 84)$ & $83.1(162 / 195)$ & 0.109 & $1.935(0.853-4.390)$ \\
\hline Perinatal death, \% (n) & $1.3(1 / 77)$ & $9.8(17 / 174)$ & 0.016 & $0.122(0.016-0.930)$ \\
\hline IUD rate, \% (n) & $1.3(1 / 77)$ & $6.9(12 / 174)$ & 0.071 & $0.178(0.023-1.391)$ \\
\hline NND rate, $\%$ (n) & $0(0 / 77)$ & $2.9(5 / 174)$ & 0.327 & - \\
\hline Gestational age at delivery (weeks) & $38.5 \pm 2.1$ & $33.4 \pm 3.0$ & $<0.001$ & \\
\hline$\geq 37$ weeks, $\%(n)$ & $90.9(70 / 77)$ & $5.2(3 / 58)$ & $<0.001$ & 183.333 (45.307-741.858) \\
\hline$<37$ weeks, \% (n) & $9.1(7 / 77)$ & $94.8(55 / 58)$ & $<0.001$ & $0.005(0.001-0.022)$ \\
\hline VPB $24-31^{+6}$ weeks, $\%$ (n) & $2.6(2 / 77)$ & $22.4(13 / 58)$ & $<0.001$ & $0.092(0.020-0.428)$ \\
\hline Live birth weight (g) & $3168 \pm 557$ & $1827 \pm 441$ & $<0.001$ & \\
\hline$\geq 2500 \mathrm{~g}, \%(\mathrm{n})$ & $90.8(69 / 76)$ & $6.8(11 / 162)$ & $<0.001$ & $135.312(50.304-363.975)$ \\
\hline LBW $<2500 \mathrm{~g}, \%(\mathrm{n})$ & $9.2(7 / 76)$ & $93.2(151 / 162)$ & $<0.001$ & $0.007(0.003-0.020)$ \\
\hline VLBW $<1500 \mathrm{~g}, \%(\mathrm{n})$ & $0(0 / 76)$ & $17.9(29 / 162)$ & $<0.001$ & - \\
\hline
\end{tabular}

Group A = DCTA pregnancy reduced to MC singleton pregnancy; Group C = DCTA pregnancy were managed expectantly

$D C T A$ dichorionic triamniotic, $M C$ monochorionic, OR odds ratio, $C l$ confidence interval, IUD intrauterine death, NND neonatal death, VPB very preterm birth, $L B W$ low birth weight, VLBW very low birth weight

among the management options, the reduction of DCTA pregnancies to $\mathrm{MC}$ singleton pregnancies resulted in the lowest risks for VPB, perinatal death and LBW and in maximal GA at delivery and live birth weight.

Women with DCTA pregnancies carry both the risks associated with triplets, such as VPB, selective growth restriction and foetal malformation, and those associated with $\mathrm{MC}$ twins due to vascular anastomoses in the single placental bed, such as twin-to-twin transfusion syndrome (TTTS) and selective intrauterine growth restriction (SIUGR) [5, 29]. Patients should be informed in detail about all possible complications. Data from previous studies [30,31] demonstrated that MFPR is feasible and effective at decreasing the risk of some adverse outcomes for pregnancies with MC twins.

The most frequently applied method for MFPR is the ultrasound-guided transabdominal injection of $\mathrm{KCl}$ into the foetal heart or thoracic cavity, which has been shown to be relatively safe [32]. In the present study, MFPR was performed for 233 DCTA pregnancies using the injection technique. Ultrasound examination within $24 \mathrm{~h}$ of the procedure demonstrated that all retained MC singletons or MCDA twins were alive, and only $1.3 \%(3 / 233)$ of cases (2 cases of DCTA pregnancy reduced to a singleton pregnancy and 1 case of DCTA pregnancy reduced to a MCDA twin pregnancy) resulted in miscarriage in the subsequent 2 weeks. The procedure was technically successful in all cases.

Some studies comparing expectant management to the reduction of dichorionic (DC) triplet pregnancies to $\mathrm{MC}$ singleton pregnancies, foetal reduction resulted in a significantly decreased risk of preterm birth $(<32$ gestational weeks), a more advanced GA at delivery and an increased birth weight, as well as a non-significantly increased risk of miscarriage $(<24$ gestational weeks) [5, 30, 33]. Similarly, the present data showed that in DCTA pregnancies that were reduced to singleton pregnancies, the VPB rate decreased from 22.4 to $2.6 \%$, the GA at delivery increased from 33.4 weeks to 38.5 weeks, and the live birth weight increased from $1827 \mathrm{~g}$ to $3168 \mathrm{~g}$; the impact of foetal reduction on the miscarriage rate $(8.3$ vs. $10.8 \%$ ) was limited.

A previous systematic review and meta-analysis compared the reduction of a DCTA pregnancy to a MC twin pregnancy $(n=15)$ with expectant management $(n=200)$ and found neither a significant increase in the risk of miscarriage $(<24$ gestational weeks; 13.3 vs. $8.5 \%$, respectively) nor a significant decrease in the risk of preterm birth (<34 weeks; 46.2 vs. $51.9 \%$, respectively) [23]. In contrast, the present study showed a significant decrease in the VPB rate from 22.4 to $7.2 \%$ and a slight decrease in the miscarriage rate from 10.8 to $7.4 \%$ 
Table 3 Pregnancy and obstetric outcomes in group B and group C

\begin{tabular}{|c|c|c|c|c|}
\hline Pregnancy outcomes & Group B & Group C & $P$-value & OR $(95 \% \mathrm{Cl})$ \\
\hline Pregnancy & 149 & 65 & & \\
\hline Miscarriage rate, \% (n) & $7.4(11 / 149)$ & $10.8(7 / 65)$ & 0.412 & $0.660(0.244-1.788)$ \\
\hline Preterm birth rate, \% (n) & $47.0(70 / 149)$ & $84.6(55 / 65)$ & $<0.001$ & $0.161(0.076-0.340)$ \\
\hline Term birth rate, \% (n) & $45.6(68 / 149)$ & $4.6(3 / 65)$ & $<0.001$ & $17.350(5.212-57.756)$ \\
\hline Caesarean section rate, \% (n) & $86.2(119 / 138)$ & $87.9(51 / 58)$ & 0.749 & $0.860(0.340-2.171)$ \\
\hline Babies born & 276 & 174 & & \\
\hline Live births & 254 & 162 & & \\
\hline Live birth rate, \% (n) & $85.2(254 / 298)$ & $83.1(162 / 195)$ & 0.519 & $1.176(0.719-1.924)$ \\
\hline Perinatal death, \% (n) & $9.1(25 / 276)$ & $9.8(17 / 174)$ & 0.8 & $0.920(0.481-1.758)$ \\
\hline IUD rate, \% (n) & $8.0(22 / 276)$ & $6.9(12 / 174)$ & 0.674 & $1.169(0.563-2.427)$ \\
\hline NND rate, \% (n) & $1.1(3 / 276)$ & $2.9(5 / 174)$ & 0.270 & $0.371(0.088-1.574)$ \\
\hline Gestational age at delivery (weeks) & $35.7 \pm 3.1$ & $33.4 \pm 3.0$ & $<0.001$ & \\
\hline$\geq 37$ weeks, \% (n) & $49.3(68 / 138)$ & $5.2(3 / 58)$ & $<0.001$ & $17.810(5.316-59.665)$ \\
\hline$<37$ weeks, \% (n) & $50.7(70 / 138)$ & $94.8(55 / 58)$ & $<0.001$ & $0.056(0.017-0.188)$ \\
\hline VPB $24-31^{+6}$ weeks, \% (n) & $7.2(10 / 138)$ & $22.4(13 / 58)$ & 0.003 & $0.270(0.111-0.660)$ \\
\hline Live birth weight (g) & $2348 \pm 488$ & $1827 \pm 441$ & $<0.001$ & \\
\hline$\geq 2500 \mathrm{~g}, \%(n)$ & $41.3(105 / 254)$ & $6.8(11 / 162)$ & $<0.001$ & 9.674 (4.994-18.737) \\
\hline LBW < $2500 \mathrm{~g}, \%(\mathrm{n})$ & $58.7(149 / 254)$ & $93.2(151 / 162)$ & $<0.001$ & $0.103(0.053-0.200)$ \\
\hline VLBW < $1500 \mathrm{~g}, \%(\mathrm{n})$ & $4.3(11 / 254)$ & $17.9(29 / 162)$ & $<0.001$ & $0.208(0.100-0.429)$ \\
\hline
\end{tabular}

Group B = DCTA pregnancy reduced to MCDA twin pregnancy; Group C = DCTA pregnancy were managed expectantly

DCTA dichorionic triamniotic, MCDA monochorionic diamniotic, OR odds ratio, $C$ confidence interval, IUD intrauterine death, NND neonatal death, VPB very preterm birth, $L B W$ low birth weight, VLBW very low birth weight

among DCTA pregnancies reduced to MCDA pregnancies compared to expectant management. The differences in outcomes between the meta-analysis and the present study are potentially due to an inadequate number of patients with DCTA pregnancies reduced to MC twin pregnancies in the meta-analysis.

Reduction by the injection technique is not appropriate in women with a MC twin pregnancy because of inter-twin placental vascular anastomoses. In addition, acute haemorrhage of the surviving twin may occur soon after the death of the co-twin through placental vascular anastomoses, with consequent death or neurodevelopmental impairment [34, 35]. Women with DCTA triplet pregnancies reduced to MCDA pregnancies were exposed to the risks of TTTS and SIUGR. Relatively new vascular occlusive techniques have enabled the possibility of reducing a triplet pregnancy containing MC twins to a DC twin pregnancy $[3,36,37]$. Some studies have reported the efficiency of this new technique in women with $\mathrm{MC}$ twins; however, it potentially increases the risk of technique-associated complications and the rate of intrauterine demise of the retained co-twin [3, 34, 36]. Chaveeva P et al. [38] reported 61 DC triplet pregnancies that were reduced to DC twin pregnancies by intrafoetal laser ablation; although reduction resulted in a relatively lower miscarriage rate (3\%), $45.9 \%$ of the cases of cotwin miscarriage within the subsequent 2 weeks were likely due to incomplete vascular occlusion and retrograde haemorrhage of the survivor through placental vascular anastomoses into the dead co-twin.

Rong Li et al. [31] reported that the MFPR of DC triplet pregnancies to singleton pregnancies had better pregnancy outcomes than those reduced to DC twin pregnancies by early transvaginal embryo reduction. The safety of a singleton pregnancy was also demonstrated in the present study. Our data showed that the reduction of DCTA pregnancies to singleton pregnancies decreased the risks of LBW and perinatal death and further increased the live birth weight compared with the reduction to MCDA pregnancies. However, two meta-analyses on the perinatal outcomes of management options for DCTA triplet pregnancies (including expectant management, reduction of the $\mathrm{MC}$ twins, reduction of one $\mathrm{MC}$ twin and reduction of the foetus with a separate placenta) reported that the number of cases was insufficient to recommend one technique or management method over another or to draw definitive conclusions on perinatal outcomes $[3,23]$. For foetal reduction in DCTA triplet pregnancies, the current choice is mostly based on technical considerations and available instrumentation. 
Table 4 Pregnancy and obstetric outcomes in group A and group B

\begin{tabular}{|c|c|c|c|c|}
\hline Pregnancy outcomes & Group A & Group B & $P$-value & OR $(95 \% \mathrm{Cl})$ \\
\hline Pregnancy & 84 & 149 & & \\
\hline Miscarriage rate, \% (n) & $8.3(7 / 84)$ & $7.4(11 / 149)$ & 0.794 & $1.140(0.425-3.063)$ \\
\hline Preterm birth rate, \% (n) & $8.3(7 / 84)$ & $47.0(70 / 149)$ & $<0.001$ & $0.103(0.044-0.237)$ \\
\hline Term birth rate, \% (n) & $83.3(70 / 84)$ & $45.6(68 / 149)$ & $<0.001$ & $5.956(3.084-11.502)$ \\
\hline Caesarean section rate, \% (n) & $68.8(53 / 77)$ & $86.2(119 / 138)$ & 0.002 & $0.353(0.178-0.698)$ \\
\hline Babies born & 77 & 276 & & \\
\hline Live births & 76 & 254 & & \\
\hline Live birth rate, \% (n) & $90.5(76 / 84)$ & $85.2(254 / 298)$ & 0.216 & $1.646(0.743-3.647)$ \\
\hline Perinatal death, \% (n) & $1.3(1 / 77)$ & $9.1(25 / 276)$ & 0.021 & $0.132(0.018-0.991)$ \\
\hline IUD rate, \% (n) & $1.3(1 / 77)$ & $8.0(22 / 276)$ & 0.036 & $0.152(0.020-1.146)$ \\
\hline NND rate, \% (n) & $0(0 / 77)$ & $1.1(3 / 276)$ & 1.000 & - \\
\hline Gestational age at delivery (weeks) & $38.5 \pm 2.1$ & $35.7 \pm 3.1$ & $<0.001$ & \\
\hline$\geq 37$ weeks, \% (n) & $90.9(70 / 77)$ & $49.3(68 / 138)$ & $<0.001$ & $10.294(4.419-23.979)$ \\
\hline$<37$ weeks, \% (n) & $9.1(7 / 77)$ & $50.7(70 / 138)$ & $<0.001$ & $0.097(0.042-0.226)$ \\
\hline VPB $24-31^{+6}$ weeks, $\%$ (n) & $2.6(2 / 77)$ & $7.2(10 / 138)$ & 0.219 & $0.341(0.073-1.600)$ \\
\hline Live birth weight (g) & $3168 \pm 557$ & $2348 \pm 488$ & $<0.001$ & \\
\hline$\geq 2500 \mathrm{~g}, \%(n)$ & $90.8(69 / 76)$ & $41.3(105 / 254)$ & $<0.001$ & $13.988(6.182-31.651)$ \\
\hline LBW < 2500 g, \% (n) & $9.2(7 / 76)$ & $58.7(149 / 254)$ & $<0.001$ & $0.071(0.032-0.162)$ \\
\hline VLBW < $1500 \mathrm{~g}, \%(\mathrm{n})$ & $0(0 / 76)$ & $4.3(11 / 254)$ & 0.075 & - \\
\hline
\end{tabular}

Group A = DCTA pregnancy reduced to MC singleton pregnancy; Group B = DCTA pregnancy reduced to MCDA twin pregnancy

$D C T A$ dichorionic triamniotic, $M C$ monochorionic, MCDA monochorionic diamniotic, OR odds ratio, $C l$ confidence interval, IUD intrauterine death, NND neonatal death, VPB very preterm birth, $L B W$ low birth weight, VLBW very low birth weight

To our knowledge, this is the largest study to examine the outcomes of patients with DCTA pregnancies conceived via IVF-ET who underwent MFPR or expectant management. However, there are some limitations of this study. One limitation is the lack of data regarding morbidity among live infants, which is obviously more important than the live birth rate alone, and successful ART is defined as the delivery of a healthy and living baby by an infertile patient. In addition, our centre is only a reproductive centre, and all pregnancy outcomes were determined by telephone call or fax; therefore, we do not have reliable information about other pregnancy complications, such as gestational hypertension, gestational diabetes and premature rupture of membranes, or data on the frequency of TTTS in DCTA pregnancies reduced to MCDA pregnancies or managed expectantly. This was a retrospective analysis, and we probably missed some information regarding women who conceived DCTA triplets.

\section{Conclusion}

In summary, in women with DCTA pregnancies conceived by IVF-ET who underwent MFPR at $11-13^{+6}$ gestational weeks or were managed expectantly, reduction to either singleton or MCDA pregnancies resulted in better pregnancy outcomes than expectant management. The perinatal outcomes of DCTA pregnancies reduced to singleton pregnancies were better than those of DCTA pregnancies reduced to MCDA pregnancies. Our data can assist physicians in counselling patients with DCTA pregnancies conceived by IVFET; however, reduction is a remedial tool to decrease the risks of a MFP. We recognize that the most effective measure to prevent unnecessary MFPs is to restrict the number of embryos transferred in women undergoing ART and to encourage selective single-blastocyst transfers.

\footnotetext{
Abbreviations

ART: Assisted reproductive technology; Cl: Confidence interval; DC: Dichorionic; DCTA: Dichorionic triamniotic; ET: Embryo transfer; GA: Gestational age; HOMPs: Higher-order multiple pregnancies; IUD: Intrauterine death; IVF-ET: In vitro fertilization-embryo transfer; LBW: Low birth weight; MC: Monochorionic; MCDA: Monochorionic diamniotic; MFP: Multifoetal pregnancy; NND: Neonatal death; NT: Nuchal translucency; OR: Odds ratio; SDs: Standard deviations; SIUGR: Selective intrauterine growth restriction; TTSS: Twin-to-twin transfusion syndrome; VLBW: Very low birth weight; VPB: Very preterm birth
}

\section{Acknowledgements}

The authors are grateful to Qingqing Wu, a senior nurse at the Reproductive and Genetic Hospital of CITIC-Xiangya, Changsha City, Hunan, China, for data collection. 


\section{Authors' contributions}

PC performed the study design, literature search, data extraction, statistical analysis, and manuscript writing and revision. All authors contributed to the study design. XHL, FG and YOY interpreted the study findings, performed the overall quality assessment and revised the final manuscript. All authors have read and approved the final manuscript.

\section{Funding}

This work was supported by the Citic-Xiangya Research Fund (No: KYXM201703); the science and technology major project of the ministry of science and technology of Hunan Province, China (NO: 2017SK1030); the China Postdoctoral Science Foundation funded project (No: 2019 M652778); and the science and technology project of Health and Family Planning Commission of Hunan Province, China (No: C20180289).

\section{Availability of data and materials}

The data analysed during this study are included in the tables in this published article. The datasets used during the current study are available from the corresponding author on reasonable request.

\section{Ethics approval and consent to participate}

This study was approved by the Ethics Committee of the Reproductive and Genetic Hospital of CITIC-Xiangya (LL-SC-2019-013). The ethics committee waived the need for informed consent due to the retrospective study design. An administrative permission was acquired by our team to access the data used in this study.

\section{Consent for publication}

Not applicable.

\section{Competing interests}

The authors declare that they have no competing interests.

\section{Author details}

'Institute of Reproductive and Stem Cell Engineering, Central South University, Changsha City 410078, Hunan, China. ${ }^{2}$ Reproductive and Genetic Hospital of CITIC-Xiangya, Changsha City 410078, Hunan, China.

\section{Received: 23 July 2019 Accepted: 17 February 2020}

Published online: 17 March 2020

\section{References}

1. Blondel B, Kaminski M. Trends in the occurrence, determinants, and consequences of multiple births. Semin Perinatol. 2002;26(4):239-49.

2. Blickstein I. The worldwide impact of iatrogenic pregnancy. Int J Gynaecol Obstet. 2003;82(3):307-17.

3. Morlando M, Ferrara L, D'Antonio F, Lawin-O'Brien A, Sankaran S, Pasupathy D, Khalil A, Papageorghiou A, Kyle P, Lees C, et al. Dichorionic triplet pregnancies: risk of miscarriage and severe preterm delivery with fetal reduction versus expectant management. Outcomes of a cohort study and systematic review. BJOG Int J Obstet Gynaecol. 2015;122(8):1053-60.

4. Kupka MS, Ferraretti AP, de Mouzon J, Erb K, D'Hooghe T, Castilla JA, CalhazJorge C, De Geyter C, Goossens V, Strohmer H, et al. Assisted reproductive technology in Europe, 2010: results generated from European registers by ESHRE. Hum Reprod. 2014;29(10):2099-113.

5. van de Mheen L, Everwijn SM, Haak MC, Manten GT, Zondervan HA, Knapen MF, Engels MA, Erwich JJ, Coumans AB, van Vugt JM, et al. Outcome of multifetal pregnancy reduction in women with a Dichorionic Triamniotic triplet pregnancy to a singleton pregnancy: a retrospective Nationwide cohort study. Fetal Diagn Ther. 2016;40(2):94-9.

6. Schachter M, Raziel A, Friedler S, Strassburger D, Bern O, Ron-El R. Monozygotic twinning after assisted reproductive techniques: a phenomenon independent of micromanipulation. Hum Reprod. 2001;16(6): 1264-9.

7. Mateizel I, Santos-Ribeiro S, Done E, Van Landuyt L, Van de Velde H, Tournaye $H$, Verheyen G. Do ARTs affect the incidence of monozygotic twinning? Hum Reprod. 2016;31(11):2435-41.

8. Busnelli A, Dallagiovanna C, Reschini M, Paffoni A, Fedele L, Somigliana E. Risk factors for monozygotic twinning after in vitro fertilization: a systematic review and meta-analysis. Fertil Steril. 2019;111(2):302-17.
9. Walker MC, Murphy KE, Pan S, Yang Q, Wen SW. SHORT COMMUNICATION: adverse maternal outcomes in multifetal pregnancies. BJOG Int J Obstet Gynaecol. 2004;111(11):1294-6.

10. Norwitz ER, Edusa V, Park JS. Maternal physiology and complications of multiple pregnancy. Semin Perinatol. 2005;29(5):338-48.

11. Papageorghiou AT, Avgidou K, Bakoulas V, Sebire NJ, Nicolaides KH. Risks of miscarriage and early preterm birth in trichorionic triplet pregnancies with embryo reduction versus expectant management: new data and systematic review. Hum Reprod. 2006;21(7):1912-7.

12. Luke B, Brown MB. Maternal morbidity and infant death in twin vs triplet and quadruplet pregnancies. Am J Obstet Gynecol. 2008;198(4):401.

13. Chambers GM, Hoang VP, Lee E, Hansen M, Sullivan EA, Bower C, Chapman M. Hospital costs of multiple-birth and singleton-birth children during the first 5 years of life and the role of assisted reproductive technology. JAMA Pediatr. 2014;168(11):1045

14. Strauss A, Paek BW, Genzel-Boroviczény O, Schulze A, Janssen U, Hepp H. Multifetal gestation - maternal and perinatal outcome of 112 pregnancies. Fetal Diagn Ther. 2002;17(4):209-17.

15. Blickstein I. How and why are triplets disadvantaged compared to twins? Best Pract Res Clin Obstet Gynaecol. 2004;18(4):631-44.

16. van de Mheen L, Everwijn SM, Knapen MF, Oepkes D, Engels M, Manten GT, Zondervan H, Wirjosoekarto SA, van Vugt JM, Erwich JJ, et al. The effectiveness of multifetal pregnancy reduction in trichorionic triplet gestation. Am J Obstet Gynecol. 2014;211(5):531-6.

17. Razaz N, Avitan T, Ting J, Pressey T, Joseph KS. Perinatal outcomes in multifetal pregnancy following fetal reduction. CMAJ. 2017;189(18):E652-8.

18. Kanhai HH, van Rijssel EJ, Meerman RJ, Bennebroek GJ. Selective termination in quintuplet pregnancy during first trimester. LANCET. 1986; 1(8495): 1447.

19. Evans MI, Britt DW. Fetal reduction 2008. Curr Opin Obstet Gynecol. 2008; 20(4):386-93.

20. Coffler MS, Kol S, Drugan A, Itskovitz-Eldor J. Early transvaginal embryo aspiration: a safer method for selective reduction in high order multiple gestations. Hum Reprod. 1999;14(7):1875-8.

21. Mansour RT, Aboulghar MA, Serour Gl, Sattar MA, Kamal A, Amin YM. Multifetal pregnancy reduction: modification of the technique and analysis of the outcome. Fertil Steril. 1999;71(2):380-4.

22. Melgar CA, Rosenfeld DL, Rawlinson K, Greenberg M. Perinatal outcome after multifetal reduction to twins compared with nonreduced multiple gestations. Obstet Gynecol. 1991;78(5 Pt 1):763-7.

23. Anthoulakis C, Dagklis T, Mamopoulos A, Athanasiadis A. Risks of miscarriage or preterm delivery in trichorionic and dichorionic triplet pregnancies with embryo reduction versus expectant management: a systematic review and meta-analysis. Hum Reprod. 2017;32(6):1351-9.

24. Li X, Ouyang Y, Yi Y, Lin G, Lu G, Gong F. Pregnancy outcomes of women with a congenital unicornuate uterus after IVF-embryo transfer. Reprod BioMed Online. 2017;35(5):583-91.

25. Shetty A, Smith APM. The sonographic diagnosis of chorionicity. Prenatal Diag. 2005;25(9):735-9.

26. Taipale P, Hiilesmaa V, Salonen R, Ylostalo P. Increased nuchal translucency as a marker for fetal chromosomal defects. N Engl J Med. 1997;337(23): 1654-8.

27. D'Antonio F, Odibo A, Berghella V, Khalil A, Hack K, Saccone G, Prefumo F, Buca D, Liberati M, Pagani G, et al. Perinatal mortality, timing of delivery and prenatal management of monoamniotic twin pregnancy: systematic review and meta-analysis. Ultrasound Obstet Gynecol. 2019;53(2):166-74.

28. Zegers-Hochschild F, Adamson GD, de Mouzon J, Ishihara O, Mansour R, Nygren K, Sullivan E, Vanderpoel S. International Committee for Monitoring Assisted Reproductive Technology (ICMART) and the World Health Organization (WHO) revised glossary of ART terminology, 2009*. Fertil Steril. 2009:92(5):1520-4

29. Lopriore E, Middeldorp JM, Oepkes D, Kanhai HH, Walther FJ, Vandenbussche FPHA. Twin anemia-polycythemia sequence in two Monochorionic twin pairs without Oligo-Polyhydramnios sequence. PLACENTA. 2007;28(1):47-51.

30. Athanasiadis AP, Zafrakas M, Tarlatzis BC, Vaitsi V, Mikos T, Bontis J. Multifetal pregnancy reduction in pregnancies with a monochorionic component. Fertil Steril. 2005:83(2):474-6.

31. Li R, Chen X, Yang S, Yang R, Ma C, Liu P, Qiao J. Retain singleton or twins? Multifetal pregnancy reduction strategies in triplet pregnancies with monochorionic twins. Eur J Obstet Gynecol Reprod Biol. 2013;167(2):146-8. 
32. Yaron Y, Bryant-Greenwood PK, Dave N, Moldenhauer JS, Kramer RL, Johnson MP, Evans MI. Multifetal pregnancy reductions of triplets to twins: comparison with nonreduced triplets and twins. Am J Obstet Gynecol. 1999;180(5):1268-71.

33. Skiadas CC, Missmer SA, Benson CB, Acker D, Racowsky C. Impact of selective reduction of the monochorionic pair in in vitro fertilization triplet pregnancies on gestational length. Fertil Steril. 2010;94(7):2930-1.

34. Rossi AC, D'Addario V. Umbilical cord occlusion for selective feticide in complicated monochorionic twins: a systematic review of literature. Am J Obstet Gynecol. 2009;200(2):123-9.

35. Lin H, Wen Y, Li Y, Chen X, Yang D, Zhang Q. Early fetal reduction of dichorionic triplets to dichorionic twin or singleton pregnancies: a retrospective study. Reprod BioMed Online. 2016;32(5):490-5.

36. Chaveeva P, Kosinski P, Birdir C, Orosz L, Nicolaides KH. Embryo reduction in dichorionic triplets to dichorionic twins by intrafetal laser. Fetal Diagn Ther. 2014;35(2):83-6

37. Tse WT, Law LW, Sahota DS, Leung TY, Cheng YK. Triplet pregnancy with fetal reduction: experience in Hong Kong. Hong Kong Med J. 2017;23(4): 326-32.

38. Chaveeva P, Peeva G, Pugliese SG, Shterev A, Nicolaides KH. Intrafetal laser ablation for embryo reduction from dichorionic triplets to dichorionic twins. Ultrasound Obstet Gynecol. 2017;50(5):632-4.

\section{Publisher's Note}

Springer Nature remains neutral with regard to jurisdictional claims in published maps and institutional affiliations.

Ready to submit your research? Choose BMC and benefit from:

- fast, convenient online submission

- thorough peer review by experienced researchers in your field

- rapid publication on acceptance

- support for research data, including large and complex data types

- gold Open Access which fosters wider collaboration and increased citations

- maximum visibility for your research: over $100 \mathrm{M}$ website views per year

At BMC, research is always in progress.

Learn more biomedcentral.com/submissions 